\title{
The modified risk factors of ischemic stroke
}

\section{Zarina Babaeva $^{1}$, Yerzhan Uteuliyev ${ }^{1}$, Latina Tekebaeva ${ }^{1}$, Kairat Karibaev ${ }^{2}$}

${ }^{1}$ Kazakhstan Medical University "Higher School of Public Healthcare", Almaty, Republic of Kazakhstan ${ }^{2}$ Central Clinical Hospital of President's Affairs Administration of the Republic of Kazakhstan, Almaty, Republic of Kazakhstan

\section{Abstract}

Strokes, being a heterogeneous syndrome, are the result of multifactorial accumulative disorders of the body. The urgency of the problem of cerebral stroke is due to the high level of occurrence and prevalence on a global scale, as well as the consequences. Thus, vascular diseases of the brain vessels occupy the second place in the structure of mortality from diseases of the circulatory system and total mortality of the population. The expected aging of the population, coupled with a decrease in mortality from stroke, creates a predisposition to an increase in the burden of strokes in the form of an increase in the number of victims.

In Kazakhstan, as in most countries of the world, ischemic strokes prevail, which are the main cause of disability of the working-age population. Despite certain advances in the treatment of brain catastrophes caused by the introduction of protocols for early diagnosis and the development of algorithms for urgent actions, as well as the development of innovative pharmaceutical approaches, prevention of stroke development remains the most effective approach in all respects - medical, economic, social.

Risk factors for stroke can be classified as changeable (modifiable) and not subject to change (non-modifiable, or risk markers). Age, gender and race, ethnicity, genetic predisposition are unchangeable risk factors for both ischemic and hemorrhagic stroke, while hypertension, smoking, diet and physical inactivity are among the most common modifiable risk factors.

Stroke prevention mainly focuses on managing variable risk factors. Lifestyles and behavior modification, such as changes in diet or smoking cessation, not only reduce stroke risk, but also reduce the risk of other cardiovascular diseases. Other preventive areas include the identification and treatment of diseases that increase the risk of stroke, such as hypertension, diabetes and atrial fibrillation.

Key words: cerebral stroke, ischemic stroke, risk factors, modifiable risk factors, arterial hypertension, diabetes mellitus, dyslipidemia, atrial fibrillation

\section{ИШЕМИЯЛЫҚ ИНСУЛЬТТІН ӨЗГЕРТІЛІК ҚАУІП-ҚАТЕР ФАКТОРЛАРЫ}

Бабаева 3.Б. ${ }^{1}$, Утеулиев Е.С. ${ }^{1}$, Текебаева Л.А. ${ }^{1}$, Карибаев К.Р. ${ }^{2}$

${ }^{1}$ Қазақстандық медицина университеті «Қоғамдық денсаулық сақтау жоғары мектебі», Алматы, Қазақстан Республикасы

${ }^{2}$ Қазақстан Республикасы Президенті Іс басқармасы Орталық клиникалық ауруханасы, Алматы, Қазақстан Республикасы

\section{ТҰЖЫРЫМДАМА}

Гиперогенді синдром болып табылатын ми соққылары ағзаның көпфакторлы жинақталған бұзылыстары болып табылады. Церебральді инсульт проблемасының өзектілігі жаһандық масштабта пайда болудың және таралудың жоғары деңгейімен, сондай-ақ оның салдарымен байланысты. Ми қан тамырлары аурулары қан айналымы жүйесі ауруларынан және жалпы өлім-жітімнен өлім құрылымында екінші орын алады. Халықтың күтілетін қартаюы, инсульттан өлімнің төмендеуімен қатар, құрбандардың санын көбейту түріндегі инсульт жүктемесінің өсуіне бейімділікті тудырады.

Қазақстанда, әлемнің көптеген елдеріндегідей, жұмысшы жастағы мүгедектіктің негізгі себебі болып табылатын ишемиялық инсульттар басым. Ерте диагностикалау және жедел іс-әрекеттерге арналған алгоритмдерді әзірлеу, сондай-ақ инновациялық фрармацевтикалық әдістерді дамыту, инсульттің дамуын болдырмау үшін мидың апатқа ұшырауының белгілі бір жетістіктеріне қарамастан, медициналық, экономикалық, әлеуметтік барлық жағынан ең тиімді тәсіл болып қала бермек.

Инсульт үшін қауіпті факторлар ауысымдық (өзгеретін) ретінде жіктелуі мүмкін және өзгертілуі мүмкін емес (өзгермейтін немесе тәуекел таңбалары). Жыныс, жыныс және нәсіл, этностық, генетикалық бейімділік - бұл гипертония, темекі шегу, диета және физикалық тұрақсыздық сияқты жиі кездесетін өзгеретін қауіп фракторларының бірі болып табылатын, ишемиялық және геморрагиялық инсульт үшін өзгермейтін қауіп факторлары. 
Инсульттің алдын алу негізінен ауыспалы тәуекел фракторларын басқаруға бағытталған. Өмір салты мен мінез-құлықтың өзгеруі, мысалы, диетадағы өзгерістер немесе темекі шегуді тоқтату, инсульт тәуекелін азайтпайды, сонымен қатар басқа жүрек-қан тамырлары ауруларының қаупін азайтады. Басқа да профилактикалық бағыттар гипертония, қант диабеті және атриальді фрибриляция сияқты инсульт тәуекелін арттыратын ауруларды анықтау мен емдеуді қамтиды.

Негізгі сөздер: церебральді инсульт, ишемиялық инсульт, тәуекел факторлары, өзгеретін тәуекел фракторлары, артериялық гипертензия, қант диабеті, дислипидемия, атриальды фибрилляция

\section{МОДИФИЦИРУЕМЫЕ ФАКТОРЫ РИСКА ИШЕМИЧЕСКОГО ИНСУЛЬТА}

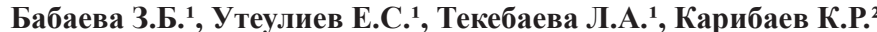

'Казахстанский медицинский университет «Высшая школа общественного здравоохранения», Алматы, Республика Казахстан

${ }^{2}$ Центральная клиническая больница медицинского центра Управления делами Президента Республики Казахстан, Алматы, Республика Казахстан

\section{PEЗЮME}

Мозговые инсульты, являясь гетерогенным синдромом, являются следствием многофракторных накопительных нарушений жизнедеятельности организма. Актуальность проблемы мозговых инсультов обусловлена высоким уровнем возникновения и распространенности в мировом масштабе, а также своими последствиями. Так, сосудистые заболевания сосудов мозга занимают второе место в структуре смертности от болезней системы кровообращения и общей смертности населения. Ожидаемое старение населения вкупе со снижением смертности от инсультов формирует предрасположенность к увеличению бремени инсультов в виде увеличения числа пострадавших

В Казахстане, как и в большинстве стран мира, преобладают ишемические инсульты, являющиеся главной причиной инвалидизации трудоспособного населения. Несмотря на определенные достижения в терапии мозговых катастроф, обусловленных внедрением протоколов ранней диагностики и разработкой алгоритмов неотложных действий, а также развитием инновационных фрармацевтических подходов, профилактика развития инсультов остается наиболее эффективным подходом во всех отношениях - медицинских, экономических, социальных.

Факторы риска развития инсульта могут быть классифицированы как изменяемые (модифицируемые) и не подлежащие изменению (немодифицируемые, или риск-маркеры). Возраст, пол и раса, этническая принадлежность, генетическая предрасположенность являются неизменяемыми факторами риска как для ишемического, так и для геморрагического инсульта, тогда как гипертония, курение, диета и физическая пассивность являются одними из наиболее часто встречающихся модифицируемых факторов риска.

Предупреждение инсультов в основном фокусируется на управлении изменяемыми риск-факторами. Образ жизни и модификация поведения, такие как изменения в диете или прекращение курения, не только уменьшают инсульт риск, но также снижает риск других сердечно-сосудистых заболеваний. Другие превентивные направления включают выявление и лечение заболеваний, увеличивающих риск развития инсульта, таких как гипертензия, диабет и фиирилляция предсердий.

Ключевые слова: мозговые инсульты, ишемический инсульт, ффакторы риска, модифицируемые риск-фракторы, артериальная гипертензия, сахарный диабет, дислипидемия, фиирилляция предсердий

\section{Введение}

Мозговой инсульт (МИ) - представитель наиболее тяжелых форм цереброваскулярных заболеваний, является одной из лидирующих причин заболеваемости и преждевременной смертности в мире [1].

Исследования последнего десятилетия демонстрируют некоторые изменения в эпидемиологии данного заболевания. V.Feigin et all в своем исследовании, базированном на данных GBD (Global Burden of Disease) 2013 Study продемонстрировали снижение эпидемиологических показателей мозгового инсульта в динамике, таких как заболеваемость, распространенность, смертность, и показатель потерянных лет жизни (DALY) от инсульта за период 1990 по 2013 год в некоторых странах [2]. Вместе с тем, общая тяжесть инсульта с точки зрения абсолютного числа людей, затронутых или оставшихся инвалидами, остается прежней и растет в социо-экономическом показателе. Ожидается, что старение населения, в сочетании со снижением смертности после инсульта, увеличит распространенность инсульта на 3,4 миллиона человек в период между 2012 и 2030 годами [3, 4].

В мировом масштабе в 2013 году было 6,5 млн. смертей от инсульта, что сделало инсульт второй по значимости причиной смерти после ишемической болезни сердца [5].

Согласно данным глобального доклада о состоянии неинфекционных болезней, в 2014 году 38\% причин смертности от всех сердечно-сосудистых заболеваний были вызваны МИ. (Global status report on noncommunicable diseases 2014).

Кроме этого, МИ, являясь третьей по значимости причиной инвалидизации в мире (Lozano R. 2010), представляют собой одну из первых причин долговременной инвалидности взрослых в социально развитых странах. Так, выжившие пациенты с инсультом нуждаются в помощи в повседневной жизни, которая должна предоставляться членами семьи, системой здравоохранения или другими социальными учреждениями. Обращает внимание значимая частота МИ среди работоспособного населения (11\% по данным STEPS Stroke) [6]. У 46\% пациентов в возрасте 65 лет спустя 6 месяцев после инсульта отмечается дефицит когнитивной функции мозга [7].

Исследование Feigin V.L., проведенное за период 19902010 гг. показало, что частота инсультов снизилась на $12 \%$ в странах с высоким доходом и увеличилась на $12 \%$ в странах с низким и средним уровнем доходов стран, составляя $68,6 \%$ из 16,9 млн. человек с впервые диагностированным инсультом. Кроме того, 70,9\% от 5,9 млн смертей от инсульта также приходится на страны с низким и средним уровнем доходов [8].

Для Республики Казахстан проблема МИ не менее актуальна. В 2014 году в РК было зарегистрировано 132000 смертей, наступивших от неинфекционных заболеваний. При этом, более половины случаев смертности наступило вследствие кардиоваскулярной патологии (54\%), а из них $13 \%$ - от цереброваскулярных заболеваний [9].

Согласно данным РЦРЗ, заболеваемость от инсультов за 2016 год по РК отмечена в 226,6 случаев на 100 тыс. населения (Аналитический материал расширенной коллегии Министерства здравоохранения Республики Казахстан, 2017 год).

Смертность от инсультов в РК, одна из высоких в мире, в 2017 году составила 65,77 на 100 тыс. населения. При этом имеется некоторая разница в показателях смертности от инсульта среди городского (76,37 на 100 тыс.) и сельского (51,55 на 100 тыс.) населения [10]. 


\section{Классификация фракторов риска}

Инсульт связан с многочисленными факторами риска. Американская Ассоциация сердца/ Американская Ассоциация инсульта (Guidelines for the primary prevention of stroke: a guideline for healthcare professionals from the American Heart Association/American Stroke Association) систематизировала и классифицировала факторы риска в соответствии с потенциалом для модификации образованием, обучением и консультированием (неизменяемые, изменяемые или частично изменяемые) и уровнем доказательств (подтверждено документально или менее хорошо документированы) [11, 12].

Согласно данной классификации, к неизменяемым факторам риска отнесены: возраст, пол, низкий вес при рождении, раса, этническая принадлежность и генетическая предрасположенность, географическое расположение.

К хорошо документированным и модифицируемым факторам риска авторы отнесли следующие состояния: артериальная гипертензия, сахарный диабет, физическая пассивность, дислипидемия, нарушение диеты, ожирение и распределение жировой клетчатки, курение, фибрилляция предсердий, другая сердечная патология (острый инфаркт миокарда, ишемическая и неишемическая кардиомиопатия; клапанный патологии сердца, включая наличие протезных клапанов и инфекционный эндокардит; открытое овальное окно, аневризмы предсердной перегородки; атеросклероза аорты).

Менее хорошо документированные или потенциально изменяемые факторы риска: мигрень, метаболический синдром, употребление алкоголя, прием наркотических препаратов, эпизоды апноэ во сне, гипергомоцистеинемия, повышение липопротеида (a), наследственная и приобретенная гиперкоагуляция, воспаление и инфекция.

Кроме этого, согласно классификации Feigin et al (2014), модифицируемые факторы риска также могут рассматриваться как поведенческие, метаболические и экологические, а также как краткосрочные риски или триггеры (например, инфекционные события, сепсис и стресс), среднесрочные риск-факторы (например, гипертония и гиперлипидемия) и долгосрочные рискфакторы инсульта (например, пол и раса). Факторы риска развития инсульта у молодых также, вероятно, отличаются от таковых у пожилых пациентов.

\section{Модифицируемые фракторы риска}

Согласно данным Feigen et al, более 90\% случаев первичного инсульта связаны с модифицируемыми факторами риска, из общего числа которых 75\% случаев связаны с поведенческими факторами риска. Управление поведенческими и метаболическими факторами риска с помощью изменений образа жизни может потенциально предотвратить до 75\% общей нагрузки на ход [13].

Первичная профилактика инсульта - борьба с основными факторами риска, представляется наиболее целесообразной по своей эффективности и экономической выгоде, являясь наилучшим подходом для снижения бремени инсульта, связанной с высокой инцидентностью и инвалидностью [14].

Исследования по контролю и управлению некоторыми модифицируемыми факторами риска демонстрируют многообещающие результаты. Согласно международному исследованию INTERSTROKE, выполненном в 22 странах мира в 2010 году, включающему 6000 человек, десять факторов риска связаны с 90\% риска развития инсульта [15]. Исследователи обнаружили, что гипертония, продолжающееся в настоящем курение, соотношение объема талии и бедер, оценка риска диеты, нерегулярная физическая активность, диабет, потребление алкоголя, психосоциальный стресс и депрессия, заболевания сердца, и соотношение аполипопротеина В к А1, входящих в состав липопротеинов, были связаны с повышенным риском ишемического инсульта. Риск-факторы для внутримозгового кровоизлияния включали гипертонию, курение, диету и злоупотребление алкоголем.

Достаточно много известно о факторах риска длительного развития инсульта, таких как гипертония, диабет, атеросклероз и гораздо меньше известно о краткосрочных факторах риска, или триггерах, для инсульта [16].

В данной работе авторы предлагают рассмотреть важные модифицируемые риск-факторы: артериальная гипертензия, сахарный диабет и фибрилляция предсердий.

Артериальная гипертензия (АГ), являясь одним из наиболее важных модифицируемых факторов риска как для ишемического, так и для геморрагического инсульта, упоминается в $50 \%$ потенциально предотвратимых случаев развития первичных и вторичных инсультов [17]. Так, АГ, представленная как самый влиятельный фактор риска развития МИ в исследовании, был диагностирован у 92,5\% больных инсультом [15]. Результаты исследований показали, что при среднем снижении показателей артериального давления (АД) на 5-6 мм рт. ст. для диастолического АД и 10-12 мм рт. ст. для систолического АД в течение 3-5 лет уменьшало риск развития МИ на 31,0\%. [18].

Когортное исследование Suita Study, проведенное за период 1989-2007 годов и включающее городское население - 5783 мужчин и женщин, продемонстрировало, что риск возникновения инсульта в остаточном периоде жизни (the lifetime risk) для мужчин без гипертонии в возрасте 45 лет составлял 17,21\%, а для гипертензивных мужчин - 32,79\%. Среди пациентов с гипертонической болезнью у пациентов с АГ второй степени или выше риск возникновения инсульта в течение жизни был более высоким, чем у пациентов с АГ I степени. Этот показатель развития инсульта для пациентов с АГ наблюдался также среди женщин и среди всех возрастных индексов. Исследование показало, что в данном городском населении АГ оказывает значительное влияние на риск возникновения инсульта в остаточном периоде жизни среди мужчин и женщин среднего возраста, особенно при ишемическом инсульте. [19].

The National Institute for Health and Care Excellence (NICE), 2008, рекомендует регулярный скрининг артериального давления и лечение людей с гипертонией, которые сочетают в себе модификацию образа жизни и фармакологическую терапию. Согласно рекомендации NICE, пациенты с артериальной гипертензией подлежат лекарственному контролю давления для достижения константы <140/90 мм рт. ст. (150/90 мм рт.ст. для лиц старше 80 лет) (NICE, 2008). Согласно данным исследователей, у пациентов с систолическим артериальным давлением выше 150 мм рт.ст или диастолическим давлением выше 90 мм рт.ст. или уровнем холестерина в крови более 5,0 ммоль/л лечение препаратами снижает относительный риск сердечно-сосудистых событий на одну четверть и одну треть [20, 21].

Было выявлено, что снижение АД на 10-15 мм рт.ст. (систолическое) и 5-8 мм рт.ст. (диастолическое) 
и холестерина в крови примерно на 20\% путем комбинированного лечения антигипертензивными и статинами снижало бы заболеваемость и смертность от сердечно-сосудистых заболеваний до 50\% [22]. Ориентация на пациентов с высоким риском сердечно-сосудистых заболеваний является важной задачей в плане стратификации риска [23].

Katsanos AN et al (2017) провели систематический обзор и мета регрессионный анализ влияния снижения АД с рецидивами инсульта и сердечно-сосудистых заболеваний с использованием данных рандомизированных контролируемых клинических испытаний по профилактике вторичного инсульта [24]. В их исследовании в парных метаанализах антигипертензивная терапия снизила риск повторного инсульта с инвалидизацией или смертельным исходом и сердечно-сосудистой смерти. В мета регрессионном анализе систолическое снижение АД было линейно связано с меньшим риском рецидивного инсульта, инфаркта миокарда, смертельного исхода. Аналогичным образом, диастолическое снижение АД было связано с меньшим риском рецидивного инсульта и смертности от всех причин. В целом, степень снижения АД была связана с величиной снижения риска рецидивов цереброваскулярных и сердечно-сосудистых событий.

Сахарный диабет (СД) является одним из значимых риск-факторов в природе развития мозговых инсультов

Отмечаемое распространенное ожирение среди населения во всем мире обуславливает соответствующее увеличение уровня диабета, который в свою очередь вызывает различные микро- и макрососудистые изменения. Гипергликемия по своей эпидемиологической и клинической значимости является одним из основных факторов риска развития инсульта $[25,26]$.

Индекс массы тела $\geq 25 \mathrm{\kappa} / \mathrm{M}^{2}$ коррелирует с возрастанием риска развития мозгового инсульта, прежде всего по причине увеличения частоты развития артериальной гипертензии и сахарного диабета. В метаанализе P. Strazzullo, с вовлечением 2 миллионов участников, продемонстрировано, что избыточная масса тела и ожирение ассоциированы с прогрессирующим повышением риска развития ишемического инсульта независимо от возраста, образа жизни и других факторов сердечно-сосудистых заболеваний [27].

В исследовании Putaala J (2011) было показано, что гипертензия и инсульт более часто встречаются у пациентов с СД [28]. Так, больные СД 1 типа были более подвержены развитию ишемической болезни сердца и АГ, а пациенты с СД 2 типа - ожирению, артериальной гипертензии периферических сосудов, транзиторным ишемическим атакам (ТИА) и инсультам, обусловленным атеросклерозом крупных артерий.

Проспективное исследование Akpalu J (2018) продемонстрировало более низкую выживаемость у пациентов с СД по сравнению с пациентами без диабета [29].

В работе Kaarisalo MM (2005), включающей 4390 пациентов с ишемическим инсультом, из которых у 25,1\% имелся диабет, были изучены результаты смертности на протяжении 4 недель после начала острого инсульта. СД был связан с более высоким риском смерти и инвалидности после начала инсульта [30].

Таким образом, исследования показывают, что СД является отчетливым риск-фактором у пациентов с ишемическим инсультом и обуславливает худший сосудистый прогноз, чем у пациентов с недиабетической болезнью.

В наблюдательных эпидемиологических исследованиях снижение холестерина в крови связано с уменьшением риска развития ишемической болезни сердца [31]. Липопротеин (а), являясь проатеросклеротическим и протромботическим, продемонстрировал причинную связь повышенного уровня липопротеида (а) с риском ишемической болезни сердца (ИБС) и инсульта [32].

При этом, в своем исследовании Aronis K (2017) выявил, что высокие уровни липопротеида (а) были связаны с повышенным риском ишемического инсульта среди пациентов без фибрилляции предсердий. [33]

Фибрилляция предсердий (ФП) является наиболее распространенной аритмией в клинической практике. ФП чаще представляется как часть разнообразного клинического спектра сердечно-сосудистых заболеваний, связанных со структурным и электрическим ремоделированием в левом предсердии, что приводит к возникновению и прогрессированию ФП [34]. Артериальная гипертензия, часто диагностируемая в общей популяции с ФП, играет значительную роль в патогенезе ФП и ее осложнениях. Гипертензия и ФП независимо друг от друга повышают риск цереброваскулярных событий, в том числе инсульта. Кроме того, сочетание АГ и ФП неминуемо усложняют проведение процедур первичной и вторичной профилактики инсультов, ввиду повышенного риска возникновения осложнений при гипертонической болезни в виде кровотечений при проведении антитромботической профилактики ФП.

Согласно данным Diener HC et al (2013), в профилактике первичного и вторичного инсульта у пациентов с ФП применение пероральной антикоагуляции с антагонистами витамина К (варфарин, фенпрокумон) демонстрирует относительное снижение риска инсульта на 60-70\% по сравнению с плацебо, а также снижение смертности на $26 \%$ [35]. В настоящее время ведутся исследования по использованию ингибиторов прямого фактора Ха и прямых ингибиторов тромбина (RE-LY, ROCKET-AF, AVERROES, ARISTOTLE), дающие многообещающие результаты для новых агентов, включая более высокую эффективность и значительно меньшее количество внутричерепных кровотечений по сравнению с варфарином. Новые вещества показывают сходные результаты во вторичных случаях, как при первичной профилактике инсульта у пациентов с фибрилляцией предсердий.

Большое клиническое значение имеют сочетанные риск-факторы. Некоторыми авторами были проведены исследования на территории разных стран и городов для определения приоритетных профилей факторов риска. В ретроспективном исследовании Habibi-Koolaee M (2018) 375 пациентов с инсультом, проведенном за период 20152016 г, гипертензия, сахарный диабет и дислипидемия были признаны основными факторами риска ишемического инсульта в регионе (Северо-Восточный Иран) [36]. В исследовании, проведенном в Китайской Народной Республике, были выявлены три основных фактора риска развития цереброваскулярных заболеваний - дислипидемия, курение и гипертония [37].

\section{Заключение}

Оценка риска развития инсульта на основе оценки индивидуального сочетания факторов риска, особенно для случая возникновения инсульта впервые в жизни, является 
важным компонентом первичной медико-санитарной помощи. Стратификация групп лиц с сочетанием рискфакторов развития церебральных инсультов эффективна с точки зрения затрат на превентивные расходы с целью профилактики инвалидности ранней смерти и улучшения качества жизни в этой группе. Согласно результатам исследований, целевые вмешательства, которые снижают артериальное давление и курение, а также способствуют физической активности и здоровому питанию, могут существенно снизить бремя развития инсульта.

Первичная профилактика ишемических инсультов направлена на борьбу с известными факторами риска для предотвращения острого нарушения мозгового кровообращения у здоровых людей и пациентов с начальными формами цереброваскулярной патологии. Адекватная система лечебно-профилактической помощи населению предполагает внедрение активных мероприятий по управлению модифицируемыми факторами риска.

Учитывая модифицируемость вышеуказанных факторов, согласно классификации Американской Ассоциации сердца/Американской Ассоциации инсульта, выявление приоритетных на отдельно взятой территории факторов риска дает возможность директивным органам пересмотреть систему контроля и воздействия на эти факторы. В свою очередь, более прицельное внимание на эти компоненты в рамках усовершенствования программ первичной профилактики, в дальнейшем может дать прогнозируемо более эффективный результат по проведению превентивных мер ишемического инсульта на изученной территории. Доказанная причинно-следственная связь управляемых риск-факторов и развития мозговых инсультов у населения, а, впоследствии, значительных расходов на здравоохранение и социальных потерь, обуславливает целесообразность руководствоваться оценкой риска при разработке руководств по профилактике сосудистых заболеваний на конкретной популяции. Рекомендации по управлению основными факторами риска в виде изменения образа жизни и превентивной лекарственной терапии, должны учитывать конкретные политические, экономические, социальные и медицинские обстоятельства.

Disclosures: There is no conflict of interest for all authors.

\section{Список литературы}

1. Lopez AD, Mathers CD, Ezzati M, Jamison DT, Murray CJ. Global and regional burden of disease and risk factors, 2001: Systematic analysis of population health data. Lancet. 2006; 367:1747-1757.https://doi.org/10.1016/S0140-6736(06)68770-9

2. Feigin VL, Norrving B, Mensah GA. Global Burden of Stroke. Circulation Research. 2017; 120:439-448. https://doi.org/10.1161/ CIRCRESAHA.116.308413

3. Ovbiagele B, Goldstein LB, Higashida RT, Howard VJ, Johnston SC, Khavjou OA, et al. American Heart Association Advocacy Coordinating Committee and Stroke Council. Forecasting the future of stroke in the United States: a policy statement from the American Heart Association and American Stroke Association. Stroke. 2013;44:2361-2375. https://oi.org/10.1161/ STR.0b013e31829734f2

4. Pearson TA, Palaniappan LP, Artinian NT, Carnethon MR, Criqui MH, Daniels SR, et al. American Heart Association Council on Epidemiology and Prevention. American Heart Association Guide for Improving Cardiovascular Health at the Community Level, 2013 update: a scientific statement for public health practitioners, healthcare providers, and health policy makers. Circulation. 2013; 127:1730-1753.https://doi.org/10.1161/CIR.0b013e31828f8a94

5. Benjamin EJ, Blaha MJ, Chiuve SE, Cushman M, Das SR, Deo R, et al. Heart Disease and Stroke Statistics-2017 Update. A Report from the American Heart Association. Circulation. 2017; 135(10): e146-e603. https://doi.org/10.1161/CIR.0000000000000485

6. Truelsen T, Heuschmann PU, Bonira R, Arjundas G, Dalal P, Damasceno A. et al. Standard method for developing stroke registers in low-income and middle-income countries: experiences from a feasibility study of a stepwise approach to stroke surveillance (STEPS Stroke). The Lancet, Neurology. 2007; 6(2):134-139. https://doi.org/10.1016/S1474-4422(06)70686-X

7. Go AS, Mozaffarian D, Roger VL, Benjamin EJ, Berry JD, Blaha MJ, et al. American Heart Association Statistics Committee and Stroke Statistics Subcommittee. Heart disease and stroke statistics-2014 update: a report from the American Heart Association. Circulation. 2014; 129(3):e28-e292.https://doi.org/10.1161/01.cir.0000441139.02102.80

8. Feigin VL, Forouzanfar MH, Krishnamurthi R. Global and regional burden of stroke during 1990-2010: findings from the Global Burden of Disease Study 2010. Lancet. 2014; 18 (383):245-254.https://doi.org/10.1016/S0140-6736(13)61953-4

9. Noncommunicable diseases country profiles, $2014 \mathrm{http}: / / \mathrm{www}$. who.int/nmh/countries/kaz_en.pdf?ua=1

10. Statisticheskij sbornik «Zdorov'e naselenija Respubliki Kazahstan i dejatel'nosti organizacij zdravoohranenija v 2017 godu» (The statistical bulletin «Health in the Republic of Kazakhstan and healthcare in 2017) [in Russian].

11. Goldstein LB., Bushnell CD, Adams RJ, Appel LJ, Braun LT, Chaturvedi S et al. Guidelines for the primary prevention of stroke: a guideline for healthcare professionals from the American Heart Association/American Stroke Association. Stroke. 2011; 42(2):517-84.https://doi.org/10.1161/STR.0b013e3181fcb238

12. Meschia JF, Bushnell C, Boden-Albala B, Braun LT, Bravata DM, Chaturvedi S, et al. Guidelines for the Primary Prevention of Stroke. A Statement for Healthcare Professionals from the American Heart Association/American Stroke Association. Stroke. 2014; 45:3754-3832.https://doi.org/10.1161/STR.0000000000000046

13. Feigin VL, Krishnamurthi R, Bhattacharjee R. New strategy to reduce the global burden of stroke. Stroke. 2015; 46(9):17401747. https://doi.org/10.1161/STROKEAHA.115.008222

14. Sacco RL, Benjamin EJ, Broderick JP, Dyken M, Easton JD, Feinberg WM, et al. American Heart Association prevention conference. IV. Prevention and rehabilitation of stroke. Risk factors. Stroke. 1997; 28(7):1507-17. https://doi.org/10.1161/01. STR.28.7.1507

15. O’Donnell M, Xavier D, Liu L, Zhang H, Chin SL, Rao-Melacini P, et al. Risk factors for ischaemic and intracerebral haemorrhagic stroke in 22 countries (the INTERSTROKE Study): a case-control study. Lancet. 2010; 376:112-123. https://doi.org/10.1016/ S0140-6736(10)60834-3 
16. Elkind MS. Why now? Moving from stroke risk factors to stroke triggers. Curr Opin Neurol. 2007; 20:51-57. https://doi. org/10.1097/WCO.0b013e328012da75

17. Di Legge S, Koch G, Diomedi M, Stanzione P, Sallustio F. Stroke prevention: managing modifiable risk factors. Stroke Res Treat. 2012; 2012:391538. https://doi.org/10.1155/2012/391538

18. Sierra C, Coca A. High blood pressure, alcohol, and cardiovascular risk. Eur. Society of Hypertension Scient. Newsletter. 2011; 12(39):177-189.

19. Turin TC, Okamura T, Afzal AR, Rumana N, Watanabe M, Higashiyama A, et al. Hypertension and lifetime risk of stroke. $J$ Hypertens. 2016; 34(1):116-22. https://doi.org/10.1097/HJH.0000000000000753

20. Lewington S, Clarke R. Combined effects of systolic blood pressure and total cholesterol on cardiovascular disease risk. Circulation. 2005; 112:3373-3374.https://doi.org/10.1161/CIRCULATIONAHA.105.581934

21. Sever PS, Dahlöf B, Poulter NR, Wedel H, Beevers G, Caulfield M, et al, Prevention of coronary and stroke events with atorvastatin in hypertensive patients who have average or lower-than-average cholesterol concentrations, in the Anglo-Scandinavian Cardiac Outcomes Trial - Lipid Lowering Arm (ASCOT-LLA): a multicentre randomised controlled trial. Lancet. 2003; 361(9364):1149_ 1158.https://doi.org/10.1016/S0140-6736(03)12948-0

22. Wald NJ, Law MR. A strategy to reduce cardiovascular disease by more than 80\%. BMJ. 2003; 326(7404):1419. https://doi. org/10.1136/bmj.326.7404.1419

23. MacMahon S, Rodgers A. The effects of blood pressure reduction in older patients: an overview of five randomized controlled trials in elderly hypertensives. Clin Exp Hypertens. 1993; 15(6):967-978.https://doi.org/10.3109/10641969309037085

24. Katsanos AH, Filippatou A, Manios E, Deftereos S, Parissis J, Frogoudaki A, et al. Blood Pressure Reduction and Secondary Stroke Prevention: A Systematic Review and Metaregression Analysis of Randomized Clinical Trials. Hypertension. 2017; 69(1):171-179.https://doi.org/10.1161/HYPERTENSIONAHA.116.08485

25. Bejot Y, Giroud M. Stroke in diabetic patients. Diabetes Metab. 2010; 36:84-87.https://doi.org/10.1016/S1262-3636(10)70472-9

26. Tuttolomondo A, Pinto A, Salemi G, Di Raimondo D, Di Sciacca R, Fernandez P, et al. Diabetic and non-diabetic subjects with ischemic stroke: differences, subtype distribution and outcome. Nutr Metab Cardio vasc Dis. 2008; 18(2):152-157. https://doi. org/10.1016/j.numecd.2007.02.003

27. Strazzullo P, D’Elia L, Cairella G, Garbagnati F, Cappuccio FP, Scalfi L. Excess body weight and incidence of stroke. Meta-analysis of prospective studies with 2 million participants. Stroke. 2010; 4:15-25. https://doi.org/10.1161/STROKEAHA.109.576967

28. Putaala J, Liebkind R, Gordin D, Thorn LM, Haapaniemi E, Forsblom C, et al. Diabetes mellitus and ischemic stroke in the young: clinical features and long-term prognosis. Neurology. 2011; 76(21):1831-7.https://doi.org/10.1212/WNL.0b013e31821cccc2

29. Akpalu J, Yawson AE, Osei-Poku F, Atiase Y, Yorke E, Adjei P, et al. Stroke Outcome and Determinants among Patients with and without Diabetes in a Tertiary Hospital in Ghana. Stroke Res Treat. 2018; 7521351. https://doi.org/10.1155/2018/7521351

30. Kaarisalo MM, Räihä I, Sivenius J, Immonen-Räihä P, Lehtonen A, Sarti C, et al. Diabetes worsens the outcome of acute ischemic stroke. Diabetes Res Clin Pract. 2005; 69(3):293-8.https://doi.org/10.1016/j.diabres.2005.02.001

31. Huxley R1, Lewington S, Clarke R. Cholesterol, coronary heart disease and stroke: a review of published evidence from observational studies and randomized controlled trials. Semin Vasc Med. 2002; 2(3):315-23. https://doi.org/10.1055/s-2002-35402

32. Erqou S, Kaptoge S, Perry PL, Di Angelantonio E, Thompson A, White IR, et al. Lipoprotein (a) concentration and the risk of coronary heart disease, stroke, and nonvascular mortality. Emerging Risk Factors Collaboration. JAMA. 2009; 302(4):412-23. https://doi.org/10.1001/jama.2009.1063

33. Aronis KN, Zhao D, Hoogeveen RC, Alonso A, Ballantyne CM, Guallar E, et al. Associations of Lipoprotein(a) Levels With Incident Atrial Fibrillation and Ischemic Stroke: The ARIC (Atherosclerosis Risk in Communities) Study. J Am Heart Assoc. 2017; 6(12):e007372. https://doi.org/10.1161/JAHA.117.007372

34. Dzeshka MS, Shahid F, Shantsila A, Lip GYH. Hypertension and Atrial Fibrillation: An Intimate Association of Epidemiology, Pathophysiology, and Outcomes. Am J Hypertens. 2017; 30(8):733-755.https://doi.org/10.1093/ajh/hpx013

35. Diener HC, Weber R, Lip GY, Hohnloser SH. Stroke prevention in atrial fibrillation: do we still need warfarin? Curr Opin Neurol. 2012; 25(1):27-35. https://doi.org/10.1097/WCO.0b013e32834e604a

36. Habibi-Koolaee M, Shahmoradi L, Niakan Kalhori SR, Ghannadan H, Younesi E. Prevalence of Stroke Risk Factors and Their Distribution Based on StrokeSubtypes in Gorgan: A Retrospective Hospital-Based Study-2015-2016. Neurol Res Int. 2018; 2018:2709654. https://doi.org/10.1155/2018/2709654

37. Fu-Liang Zhang, Zhen-Ni Guo, Yan-Hua Wu, Hao-Yuan Liu, Yun Luo, Ming-Shuo Sun, et al. Prevalence of stroke and associated risk factors: a population based cross sectional study from northeast China. BMJ Open. 2017; 7(9):e015758. https:// doi.org/10.1136/bmjopen-2016-015758

How to cite this article: Zarina Babaeva, Yerzhan Uteuliyev, Latina Tekebaeva, Kairat Karibaev. The modified risk factors of ischemic stroke [in Russian]. J Clin Med Kaz. 2018; 4(50):15-20 